\title{
An Empirical Study on the Interpersonal Relationship between Customers and Staff in Professional Services in China
}

\author{
Shu-nan SONG ${ }^{1, a}$, Raymond Liu²,b and Da-hai DONG ${ }^{3, c}$ \\ ${ }^{1}$ Liaoning Normal University, Dalian, China \\ 2 University of Massachusetts Boston, Boston, America \\ 3 Dalian University of Technology, China Business Executives Academy, Dalian, China \\ ateachersong74@163.com, b raymond.liu@umb.edu, co dongdh@dlut.edu.cn
}

Keywords: IRCS, Staff trust, Staff commitment, Firm commitment.

\begin{abstract}
This study examines the interpersonal relationship between Customers and Staff in professional service in China, which differs from the Chinese "Gunxi" in the B2B field. Based on the attitude theory, this study examines the interpersonal relationship between customer and staff from both cognitive and emotional aspects. Three dimensions are proposed: Closeness, Liking and Overall Recognition, and then a conceptual model between the interpersonal relationship and customer commitment is constructed. Both the scale and the model are tested with nation-wide data. The results show that interpersonal relationship has an impact on customers' firm commitment directly and through staff trust and staff commitment indirectly. Theoretical and practical contributions of the results are discussed.
\end{abstract}

\section{Introduction}

In recent years, with the deepening of the economic structure adjustment, China's service industry has been developing rapidly. As the most populous nation, and one of the fastest growing economies its service market is very attractive to the whole world. According to Hofstede(1980), in collectivist societies, there is a greater emphasis placed on others than on the self, which leads to an emphasis on harmony, conformity and on subordination of one's own goals to those of the collective ${ }^{[1]}$. Interpersonal relationship are more important to social life in China than in western countries, and this difference extends to business area ${ }^{[2]}$. In high-contact circumstance, such as professional services, interpersonal relationship between customer and service staff develops in the process of service delivery and may have an significant effect on customers' choices.

The interpersonal relationship between business partners under B2B was one of the hottest topics about China, which was refered to as "Guanxi" ${ }^{[3,4]}$, however under B2C, the interpersonal relationship between customer and service staff (IRCS) in professional service defers from "guanxi" in many respects, and the research is very limited. The present study focuses on the former and its impact on customer commitment to both the staff and the service company in China.

\section{Theoretical Background}

2.1Characteristics of Professional Services According to Schmenner's Service Process Matrix(1986), professional services are services with high degree of labour intensity, high interaction and customization ${ }^{[5]}$. They are non-standardized and specialized services provided by people like doctor, lawyer, accountant, coach, hairdresser, financial advisor, real estate agent, message master, etc. They are normally one-to-one based at personal level, with longer service time, more frequent contact and more communications. It is more likely to build a closer interpersonal relationship in professional services than non-professional services. Therefore, the interpersonal relationship between customer and service staff plays more important role in professinal services. So we limit our study in professional services, where interpersonal relationship is more typical. 
2.2Interpersonal relationship Under $\mathrm{B} 2 \mathrm{~B}$, although researchers have different ideas on the importance of the interpersonal relationship, they propose or verify that interpersonal relationship has an impact on relationship change, customer loyalty, business communication, trust, satisfaction, and perceived service quality etc. ${ }^{[6,7]}$. Under B2C, researchers pay more attention to the specific aspects of interpersonal relationship. Besides interpersonal relationship, they use commercial friendship, relationship component, individual relationship(tactics), and interpersonal-based service encounters to demonstrate its impact ${ }^{[8,9]}$. Wan et al (2012)developed a true interpersonal relationship scale, with mutual disclosure, friendship, and common social identity as the three components ${ }^{[10]}$. Bove and Johnson(2001) examine the service literature for the use of constructs of relationship closeness, quality, and/or strength when the construct in question refers to a customer's relationship with service worker ${ }^{[11]}$. In addition, there is some research on closeness or liking which actually throw light on interpersonal relationship, whether they use interpersonal relationship in their title or text. In this case, interpersonal relationship is regarded as a category, instead of a variable ${ }^{[12-14]}$.

2.3The Conceptualization of IRCS IRCS is a psychological connection between a customer and a staff member who provides professional service for the customer, and it is formed through the interactive process of the service, and is based on personal emotion and cognition. IRCS differs from Chinese "guanxi" and western interpersonal relationship in business in many aspects(table1).

Table 1. Differences of the Relationship

\begin{tabular}{|c|c|c|c|}
\hline Comparison & Chinese "Guanxi" & $\begin{array}{ll}\text { Western } & \text { Personal } \\
\text { Relationship } & \end{array}$ & IRCS \\
\hline Relationship Base & $\begin{array}{l}\text { Blood and Social } \\
\text { Relationship }\end{array}$ & Exchange Relationship & Service Relationship \\
\hline Culture Background & Collectivism & Individualism & Collectism \\
\hline $\begin{array}{l}\text { Emotional/ } \\
\text { Instrumental }\end{array}$ & High in Instrumental & $\begin{array}{l}\text { Low in Both Emotional } \\
\text { and Instrumental }\end{array}$ & $\begin{array}{l}\text { High in Emotional and } \\
\text { Low in Instrumental }\end{array}$ \\
\hline Relationship Rule & Renqing, Face, Need & Contract and Fairness & Fairness and Need \\
\hline Relationship Capital & Strong & No & Weak \\
\hline Relationship Nature & Social Relationship & $\begin{array}{l}\text { Economical } \\
\text { Relationship }\end{array}$ & $\begin{array}{l}\text { Economical } \\
\text { Relationship }\end{array}$ \\
\hline Value Focus & $\begin{array}{l}\text { Personal and } \\
\text { Organizational Benefit }\end{array}$ & Personal Benefit & Personal Benefit \\
\hline Relationship Order & $\begin{array}{l}\text { Relationship First and } \\
\text { Then Business }\end{array}$ & $\begin{array}{l}\text { Business First and Then } \\
\text { Relationship }\end{array}$ & $\begin{array}{l}\text { Business First and Then } \\
\text { Relationship }\end{array}$ \\
\hline
\end{tabular}

The first and foremost difference, lies in the degree of being emotional or instrumental. In his model of human relationship and face, Hwang (1987) proposed three kinds of relationship: emotional relationship, instrumental relationship and mixed relationship, each with its own rules ${ }^{[15]}$. From the perspective of customer, "Guanxi"'is highly instrumental, on the contrary, IRCS is highly emotional, and western personal relationship is low both in instrumental and emotional axis. Under the influence of collectivism culture and Confucian ethics Chinese people are emotional in nature. In the high contact service consumption, although there is no foundation of normal social relationship such as genetic, geography, and industry connections, due to long-term, frequent or close contact, customers may have a real feeling towards their service staff. This is different from family affections, love affairs, or friendship, but a kind of caritas.

The rules of relationship are also different. According to the face and "ren qing" theory of Hwang(1998), there are two relationship rules, fairness and need. IRCS follows these two rules, but different from the emotion need of relatives and friends, or acquaintance of Hwang(1998), IRCS does not have ethical obligations, therefore, is not easilly tangled in the "ren qing" dilemma as"Guanxi". Influenced by the western social culture and the completeness of the contract, western relationship in the business environment pay more attention to fairness and contract. Another important differece is the relationship capital. "Guanxi" is regarded as a kind of capital, which can be rewarding, as well as storaged, accumulated and transferred ${ }^{[3]}$. Differences also exist in the nature, value and order of the relationship. 
In general, IRCS is highly emotional, which is similar with the emotional component of Hwang(1998). However, different from the ethics-based emotion of the daily life, it is less influenced by social norms and ethics, but adds more of fairness principles. It is different from the Chinese "Guanxi" which is constrained by the complicated relationship norms, such as "renqing" and face. It is simple, clear, and free in nature, without constaint or pressure. It's free to choose or not choose. It is not so rational and may not last long or be stable, but it indeed exists and affect consumers' purchase choices. Sometimes like "Guanxi", it even exists independently from the relationship between customers and the company.

Then, as an individual-leveled relationship, what is the significance of IRCS to customer-firm relationship? Does it lead to customer commitment directly or indirectly, and how? Researchers have suggested and shown that customer relationships with service workers are influential in the development of customer-firm relationship ${ }^{[16,17]}$, however, we focus on the emotional and cognitive relationship between individuals, and the mechanism they influence the customer-firm relationship. In the later part a IRCS-commitment model is proposed to throw some light on relationship marketing at individual level.

\section{Research Model and Hypothesis}

In the KMV model, commitment is central to relationship marketing ${ }^{[18]}$. Relationship commitment is defined as an enduring desire to maintain a valued relationship ${ }^{[19]}$. In this study, staff commitment refers to the customer's desire to maintain relationship with the service staff; and firm commitment refers to customer commitment to the service enterprise. And staff trust is customer trust to the service staff. How IRCS affect firm commitment is focused.

In the literature of $\mathrm{B} 2 \mathrm{~B}$ and channel field, it was proposed or verified that interpersonal relationship affect trust ${ }^{[20]}$, but it is not quite clear whether interpersonal relationship has direct impact on staff trust in the field of service consumption. Proper relationship could enhance the social contact of the two sides, reduce the uncertainty of the consequence, and suggests the service personnel's dedication for the interests of the customer; This prompts the formation of customer trust to the service staff ${ }^{[21]}$. Moreover, there is emotional connection between related people, which helps the generation of emotional trust. Therefore, we hypothesize that:

$\mathrm{H}_{1}$ :There will be a positive relationship between IRCS and staff trust.

In the cultural of collectivism, people tend to contact or work with someone who is related, because they believe that this can not only increase the social benefits, but also help to reduce the potential risks and get additional benefits (e.g. better service and additional gifts ). Researchers have different ideas about the impact of interpersonal relationship on business. Some confirmed that interpersonal relationship affect loyalty, commitment and relationship transfer ${ }^{[22,23]}$. However, some other western scholars and entrepreneurs think that social interaction has no connection with business relationship. As Rodriguez and Wilson (2002) founded American managers believed that social affairs were not important or meaningful to the formation of long-term relationship ${ }^{[20]}$. Therefore, it is necessary to verify the influence of interpersonal relationship on staff commitment and firm commitment in theory.

To a certain extent, the service staff belongs to his service firm. The communication between the customer and the service staff is usually in the service context, so the relationship between them can not be separated from the service enterprise. In addition, when there is a good relationship between the customer and the staff, the customer has a good attitude toward the factors which have a connection with them. The halo effect in psychology can explain it. Customer tends to give a better evaluation towards the service firm where his favorable service staff works. As Wirtz(2012) proposed that the first line staff understood the needs of customers, they delivered services and established interpersonal relationships, which will bring customer loyalty ${ }^{[24]}$.

Hence we hypothesize that:

$\mathrm{H}_{2}$ : There will be a positive relationship between IRCS and staff commitment.

$\mathrm{H}_{3}$ : There will be a positive relationship between IRCS and firm commitment. 
It is well established in the literature that trust will lead to commitment. We propose a similar hypothesis in the field of professional service:

$\mathrm{H}_{4}$ : There will be a positive relationship between staff trust and staff commitment.

Service staff is the representative of the enterprise, and objectively, the service staff can only provide his service with the environment, equipment, products and information provided by his enterprise, so it is necessary for the customer to stay with the service firm in order to keep the relationship with the specific service worker. From a subjective perspective, the customer will attribute favorable quality of the service staff to effective management or good corporate culture, and therefore the staff commitment is conducive to firm commitment. Therefore, we hypothesize that:

$\mathrm{H}_{5}$ : There will be a positive relationship between staff commitment and firm commitment.

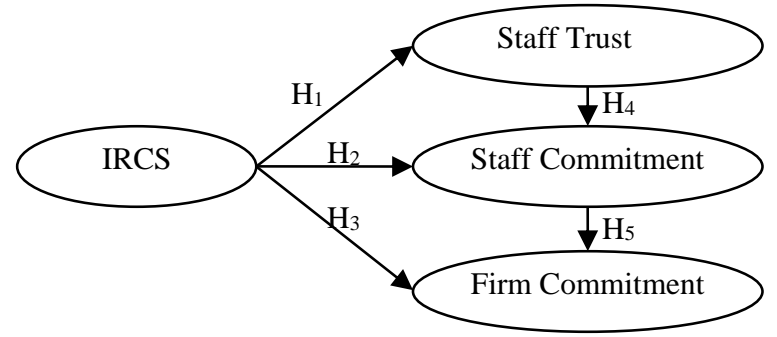

Fig. 1 The theoretic Model of the Study

\section{Method}

4.1 IRCS Dimensions and Scale Development Based on the attitude theory, this study examined the interpersonal relationship between customer and the service staff from both emotional and cognitive aspects. According to relevant literature and the results of consumer interviews, three dimensions were proposed: closeness, liking and overall recognition, among which, the first two were emotional, and the last cognitive. These three dimensions were confirmed by our depth interviews with consumers.

Closeness, here is defined as the degree of familiarity, self-disclosure and rapport that the customer feel towards the professional service worker ${ }^{[25]}$. If two people's behaviors, emotions, and thoughts are mutually and causally interconnected, the people are interdependent, then closeness exists ${ }^{[26]}$.Liking is the global affective attachment that the customer has for the service worker. It is an emotional connection that one feels for another that can be viewed as fondness or affection-a feeling that goes beyond the mere acceptance of a competent business partner. It is an attraction such that one would desire to "be around" the other out of choice, even if business ties were to terminate ${ }^{[27]}$.Overall recognition refers to one's overall understanding and agreement with another one. It is an overall assessment of another person's character and values. It is the foundation for personal relationship. We followed Churchill's(1979) guidelines to develop the measurement scale ${ }^{[28]}$.The final scale was formed after reliability and validity analysis and check, and it was tested with a nationwide data.

4.2 Data Collection and Sample Description We distributed 550 questionnaires randomly to customers in professional service centers such as hairdresser, beauty/massage parlours, training centers, clothing boutiques, financial service centers, dental clinics, fitness centers, auto repair and maintenance stores, homemaking centers, and real estate agents in six Chinese cities. We instructed the customers to finish the questionnaires, and collected the copies on spot. Altogether we collected 415 useful questionnaires with a $75.5 \%$ response rate. The samples were distributed in different service parts, with beauty/hairdresser, training and complex purchase(clothing boutiques) as the most, which account for $37.3 \%, 15.7 \%, 12.3 \%$ respectively.

4.3 Questionnaire Staff trust was measured by three items based on the scales from Yim, David and Chan (2008) ${ }^{[29]}$. Firm commitment and Staff commitment were measured by five items respectively. The items were derived from previous commitment research. These three constructs were all single dimensioned. Except those of IRCS, All the other items were translated into Chinese using the back 
translation procedure. After the pre-test, one item of staff commitment was deleted due to Cronbach's $\alpha$ of reliability analysis, and one item of firm commitment was deleted after validity analysis.

4.4 Measurement We used several measures for scale reliability, factor structure, uni-dimensionality and construct validity, such as item-total correlations, exploratory factor analysis, and confirmatory factor analysis using LISREL-8. The items and the scale properties after the scale analysis were summarized in Table2. All scales provided evidence of sufficient reliability. The estimates for composite reliability and coefficient alpha ranged from.812 to.898, which indicated that the scales had sufficient reliability for hypothesis testing. An exploratory factor analysis (EFA)(principal component Analysis with subsequent varimax rotation)was performed for the 9 items of IRCS, which led to a three-factor solution with an explained variance of 76.34 percent, with.879 as KMO. And EFA was also performed for the 3 items of staff trust, 4 items of staff commitment, 4 items of firm commitment. All items had significant loadings on the intended factors and no strong loadings on any other factor. This provided evidence of unidimensionality, and explained variances and KMOs were all satisfactory .

All measures were analyzed for validity and reliability using the confirmatory analysis. The confirmatory factor model provided a good fit for the data: $\chi^{2}(\mathrm{df}=71)=239.44, \chi^{2} / \mathrm{df}=3.37, \mathrm{p}<$ $0.001, \mathrm{GFI}=0.92, \mathrm{AGFI}=0.89, \mathrm{CFI}=0.98, \mathrm{NFI}=0.97, \mathrm{RMSEA}=0.076, \mathrm{SRMR}=0.043$. The standardized coefficients of the observed variables were between 0.69-0.90, close to or above the threshhold of 0.70 . The average variance extracted(AVE) of the factors ranged from.5624 to.7587 and surpassed the threshold of $0.50(\mathrm{p}<0.001)$. So each scale had a good convergent validity, and the results of discriminant validity analysis were also satisfactory(table3).

Table.2 The Results of Reliability, Discriminant Validity and Convergent Validity Analysis

\begin{tabular}{|c|c|c|c|c|c|c|c|}
\hline $\begin{array}{l}\text { Factor/ } \\
\text { Dimension }\end{array}$ & CITC & $\begin{array}{l}\text { Cronba } \\
\text { ch's } \alpha\end{array}$ & $\begin{array}{l}\text { Variance } \\
\text { explained }(\%)\end{array}$ & KMO & $\begin{array}{l}\text { Stand. } \\
\text { Coefficient }\end{array}$ & T-value & AVE \\
\hline IRCS & - & - & 76.34 & .879 & - & - & .5748 \\
\hline $\begin{array}{l}\text { Closeness } \\
(\mathrm{CL})\end{array}$ & $\begin{array}{l}.590 \\
.734 \\
.666 \\
\end{array}$ & .812 & - & - & 0.69 & 14.91 & - \\
\hline $\begin{array}{l}\text { Liking } \\
(\mathrm{CL})\end{array}$ & $\begin{array}{l}.686 \\
.742 \\
.700 \\
\end{array}$ & .842 & - & - & 0.79 & 17.86 & - \\
\hline $\begin{array}{l}\text { Overall } \\
\text { Recognition } \\
(\mathrm{VA})\end{array}$ & $\begin{array}{l}.672 \\
.713 \\
.692 \\
\end{array}$ & .832 & - & - & 0.79 & 17.86 & - \\
\hline $\begin{array}{l}\text { Staff } \\
\text { Trust } \\
(\text { ST) } \\
\end{array}$ & $\begin{array}{l}.760 \\
.826 \\
.817 \\
\end{array}$ & .898 & 83.80 & .740 & $\begin{array}{l}0.81 \\
0.90 \\
0.90 \\
\end{array}$ & $\begin{array}{l}19.42 \\
23.17 \\
23.05 \\
\end{array}$ & .7587 \\
\hline $\begin{array}{l}\text { Staff } \\
\text { Commitment } \\
\text { (SC) }\end{array}$ & $\begin{array}{l}.598 \\
.743 \\
.661 \\
.618 \\
\end{array}$ & .827 & 66.60 & .796 & $\begin{array}{l}0.70 \\
0.85 \\
0.73 \\
0.71 \\
\end{array}$ & \begin{tabular}{|l|}
15.56 \\
20.26 \\
16.44 \\
15.93 \\
\end{tabular} & .5624 \\
\hline $\begin{array}{l}\text { Firm } \\
\text { Commitment } \\
\text { (FC) }\end{array}$ & $\begin{array}{l}.645 \\
.706 \\
.749 \\
.657 \\
\end{array}$ & .848 & 70.47 & .785 & $\begin{array}{l}0.75 \\
0.83 \\
0.82 \\
0.72 \\
\end{array}$ & $\begin{array}{l}16.88 \\
19.60 \\
19.30 \\
16.19 \\
\end{array}$ & .6106 \\
\hline
\end{tabular}

Table. 3 The Results of Discriminant Validity Analysis

\begin{tabular}{ccccc}
\hline Construct & IRCS & ST & SC & CC \\
\hline IRCS & $\mathbf{0 . 7 6}$ & & & \\
ST & 0.73 & $\mathbf{0 . 8 7}$ & & \\
SC & 0.75 & 0.71 & $\mathbf{0 . 7 5}$ & \\
FC & 0.64 & 0.53 & 0.68 & $\mathbf{0 . 7 8}$ \\
\hline
\end{tabular}

* The data on the diagonal was the square root of the AVE value of each variable, and other data were the correlation coefficients between the variables.

4.5 Hypothesis Testing The influence of IRCS on staff commitment and firm commitment was examined using SEM. The model resulted in the following fit indexes: $\chi^{2}(\mathrm{df}=71)=239.50, \mathrm{p}<0.001$, 
$\mathrm{GFI}=0.92, \mathrm{AGFI}=0.89, \mathrm{CFI}=0.98, \mathrm{NFI}=0.97, \mathrm{RMSEA}=0.075, \chi^{2} / \mathrm{df}=3.33, \mathrm{SRMR}=0.043$. They provided evidence of reasonable fit. Table 4 provided empirical support for all the five hypothesized relationships.

Table.4 The Results of the Hypothesis Testing

\begin{tabular}{ccccc}
\hline $\mathrm{H}$ & Relation & Estimate & $\begin{array}{c}\mathrm{T}- \\
\text { value }\end{array}$ & $\begin{array}{l}\text { Testing } \\
\text { Results }\end{array}$ \\
\hline $\mathrm{H}_{1}$ & IRCS $\longleftrightarrow \mathrm{ST}$ & 0.73 & 13.27 & Support \\
$\mathrm{H}_{2}$ & IRCS $\longleftrightarrow \mathrm{SC}$ & 0.55 & 7.01 & Support \\
$\mathrm{H}_{3}$ & IRCS $\rightarrow \mathrm{FC}$ & 0.27 & 3.00 & Support \\
$\mathrm{H}_{4}$ & $\mathrm{ST} \longleftrightarrow \longrightarrow \mathrm{SC}$ & 0.31 & 4.27 & Support \\
$\mathrm{H}_{5}$ & $\mathrm{SC} \longleftarrow \rightarrow \mathrm{FC}$ & 0.47 & 4.99 & Support \\
\hline
\end{tabular}

\section{Discussion}

Most relationship marketing theory and practice emphasize the influence of firm-level factors on customer commitment, such as service quality, customer satisfaction, customer value, cost of transfer and customer trust. At individual level staff trust and staff commitment are usually regarded as the most important antecedents, while emotional and cognitive interpersonal relationship being ignored.

People being social, social factors will inevitably affect the consumer's judgment and behavior. As Iacobucci and Ostrom(1993) proposed in their paper, consumers will look for cues in the service environment to indicate the level of service quality due to the difficulty of service evaluation, and the social exchange (relationship) between the customer and the service staff is considered to be such a cue $^{[30]}$. On the other hand, with the improvement of service industry, service quality, customer satisfaction, and customer value become necessary and basic conditions for the survival of enterprises, so their status as the promoter of the enterprise competitiveness has been gradually declining. On the contrary, social measures such as the establishment and development of interpersonal relationship attach more and more importance.

5.1 Academic Implications The present study has two major academic implications. First, it enriched interpersonal relationship study in business, especially in consumer markets by defining and operationalizing the concept of IRCS. Through the empirical measurement of interpersonal relationship, we can understand the connotation and composition of interpersonal relationship between customers and their service staff more clearly, and also facilitate the exploration of connections between interpersonal relationship and other marketing variables.

Second, this study constructed a IRCS-commitment model, and identified the mechanism of the impact, enriching the research on antecedents of enterprise commitment in the service industry. Our results show that IRCS has an impact on customers' firm commitment directly and through staff trust and staff commitment indirectly. This is consistent with Bove(2006)'s finding that the positive feelings a client has towards a service worker will transfer to the service business ${ }^{[31]}$.

5.2 Managerial Implications Overall, it explains the importance of IRCS and its impact on customers' firm commitment. We remind professional service enterprises not to ignore the interpersonal factors of service personnels, when attach importance to the firm-level factors. More specifically, we suggest that firms should pay a special attention to Closeness, Liking, and Overall Recognition to build a healthy IRCS.

The results of this study show the importance of IRCS, however, it is of more practical significance that how to turn this interpersonal relationship into firm-level relationship. If customers have established a good interpersonal relationship with a particular service worker, this relationship may go beyond the service firm. In the case of turnover, the service worker may take away some customers with him unless the firm-level relationship wins. This may result in losses to the enterprise. Actually IRCS is a double-edged sword. For service enterprises, when cultivating IRCS, be sure to strengthen the relationship at firm level, and to guide IRCS to stable firm level relationship at the same time.

5.3 Limitations and Future Research The present study has a few limitations that should be overcome in future studies. The first is about the samples. We listed the typical research situations in 
professional services for the participants to choose. Future studies need to cover more parts of service industries.

The Second is about the non-relational customer. In the consumer interviews we found that although the majority of the respondents expressed clearly their emotional and cognitive connection with the service staff, there were a small number of consumers indicating that there was only service relationship between them and the service staff. It is far from interpersonal relationships, without any component of social interaction. The present study could not explain whether it is due to consumers' individual differences, different services or moderating effect of other variables. Further exploration may be needed from the perspective of psychological characteristics or personal relationship orientation.

The third one is about moderating factors. As mentioned above, this study confirmed that individual-level relationship can be converted into the customer-firm relationship, but little is known about how to promote the transformation. Therefore, to make better use of personal relationships, future research need to probe moderators of the two levels of relationships, such as the number of service workers, consistency of the service workers, corporate reputation, sense of belonging of the staff to the firm,etc.

\section{Acknowledgement}

This research was financially supported by the National Natural Science Foundation of China (Grant NO. 71272094).

\section{References}

[1] G.Hofstede, Culture's Consequences: International Differences in Work-related Values, California:Sage, 1980.

[2] G. J. Zhuang, Y. M.Xi, A. S L.Tsang, Power,conflict, and cooperation: The impact of Guanxi in a Chinese marketing channel, Industrial Marketing Management, vol. 39, pp. 137-149,2010.

[3] F. F.Gu, K.Hung, D. K.Tse, When does guanxi matter? Issues of capitalization and its dark sides, Journal of Marketing, vol.72, pp. 12-28,2008.

[4] K.Mak, S. K. S.Wong, C.Tong, How Guanxi Influences Word of Mouth Intentions, International Journal of Business and Management, vol. 6,pp. 3,2011.

[5] R.W.Schmenner, How can service businesses survive and prosper? Sloan management review, vol. 27,pp. 21-32,1986.

[6] B.Cater,The importance of social bonds for communication and trust in marketing relationships in professional services ,Management, Vol.13, pp.1-15,2008.

[7] T.Schakett, A.Flaschner, T.Gao,et al,Effects of Social Bonding in Business-to-Business Relationships, Journal of Relationship Marketing, Vol. 10, pp. 264-280,2011.

[8] S. H. S. Ali,Proactive vs Reactive Measures in Building Quality Relationship with Customers in Banking Sector, Interdisciplinary Journal of Contemporary Research in Business, Vol. 3, pp. 553-565,2011.

[9] C. H.Wang, L.C.Hsu, How do Service Encounters Impact on Relationship Benefits, International Business Research, Vol. 5, pp. 98, 2012.

[10] W.W.N.Wan, C.L.Luk,K.S.Fam,et al.Interpersonal Relationship,Service Quality,Seller Expertise: How Important Are They to Adolescent Consumers? Psychology \& Marketing, Vol.29,pp. 365377,2012 . 
[11] L.L.Bove,L.W.Johnson, Customer relationships with service personnel: do we measure closeness, quality or strength? Journal of Business Research, Vol.54, pp. 189-197,2001.

[12] J. G.Barnes, Closeness,strength,and satisfaction:examining the nature of relationships between providers of financial services and their retail customers, Psychology \& Marketing, Vol.14,pp. 765-790,1997.

[13] J. Ma.Does the customer-firm relationship affect consumer recovery expectations, Academy of Marketing Studies Journal, Vol.16,pp. 17-30,2012.

[14] C.Y.Nicholson, L. D.Compeau, R.Sethi, The role of interpersonal liking in building trust in longterm channel relationships, Journal of the Academy of Marketing Science, Vol.29,pp.3,2001.

[15] K.Hwang, Face and favor: The Chinese power game, American journal of Sociology, Vol.92,pp. 944-974,1987.

[16] L. L.Bove, L.W.Johnson, A customer-service worker relationship model, International Journal of Service Industry Management, Vol.11,pp. 491-511,2000.

[17] R.W.Palmatier, L. K.Scheer, M. B.Houston, et al. Use of relationship marketing programs in building customer-salesperson and customer-firm relationships: Differential influences on financial outcomes,International Journal of Research in Marketing, Vol.24,pp. 210-223,2007.

[18] R. M.Morgan, S. D. Hunt, The commitment-trust theory of relationship marketing, Journal of marketing, Vol.58,pp 20-38,1994.

[19] C.Moorman, G.Zaltman, R.Deshpande, Relationships between providers and users of market research: The dynamics of trust, Journal of marketing research, Vol.29,pp. 314-328,1992.

[20] C. M.Rodriguez, D. T.Wilson, Relationship Bonding and Trust as a Foundation for Commitment in U.S.-Mexican Strategic Alliances: A Structural Equation Modeling Approach, Journal of International Marketing, Vol.10,pp.53-76,2002.

[21] L. A.Crosby, R. E Kenneth, D.Cowles , Relationship Quality in Services Selling: An Interpersonal Influence Perspective, Journal of Marketing, Vol.54,pp. 68-81,1990.

[22] P.Chao, H. P.Fu, I. Y.Lu,Strengthening the Quality-Loyalty Linkage:The Role of Customer Orientation and Interpersonal Relationship, The Service Industries Journal, Vol.27,pp. 471494,2007.

[23] K. H.Wathne, H.Biong, J. B.Heide, Choice of supplier in embedded markets: relationship and marketing program effects, Journal of Marketing, Vol.65,pp. 54-66,2001.

[24] J.Wirtz, Essentials of services marketing, New Jersey :FT Press, 2012.

[25] K.Butcher, B.Sparks, F.O'Callaghan,Evaluative and relational influences on service loyalty, International Journal of Service Industry Management, Vol.12,pp. 310-327,2001.

[26] H.H.Kelley, Personal Relationships: Their Structures and Processes, New York: Lawrence Erlbaum Associates, 1979.

[27] C. Y.Nicholson, L. D.Compeau, R. Sethi,The role of interpersonal liking in building trust in long-term channel relationships, Journal of the Academy of Marketing Science, Vol.29,pp. 3,2001 .

[28] G. A. Churchill, A Paradigm for Developing Better Measures of Marketing Constructs,Journal of Marketing Research, Vol.16,pp. 64-73,1979.

[29] C. K.Yim, D. K.Tse, K. W.Chan, Strengthening customer loyalty through intimacy and passion: roles of customer-firm affection and customer-staff relationships in services,Journal of Marketing Research, Vol.45,pp. 741-756, 2008. 
[30] D. Iacobucci, A.Ostrom,Gender differences in the impact of core and relational aspects of services on the evaluation of service encounters,Journal of Consumer Psychology, Vol. 2, pp. 257-286,1993.

[31] L. L.Bove, L. W.Johnson ,Customer loyalty to one service worker: should it be discouraged? International Journal of Research in Marketing, Vol. 23,pp. 79-91,2006. 